\title{
Effect of dietary phospholipid level and phospholipid:neutral lipid value on the development of sea bass (Dicentrarchus labrax) larvae fed a compound diet
}

\author{
Chantal L. Cahu*, José L. Zambonino Infante and Valérie Barbosa \\ Unité Mixte de Nutrition des poissons IFREMER-INRA, B.P. 70, 29280 Plouzané, France
}

(Received 21 January 2002 - Revised 21 January 2003 - Accepted 4 February 2003)

\begin{abstract}
The aim of the study was to determine the influence of dietary phospholipid concentration on survival and development in sea bass (Dicentrarchus labrax) larvae. Larvae were fed from day 9 to day 40 post-hatch with an isoproteic and isolipidic formulated diet with graded phospholipid levels from 27 to $116 \mathrm{~g} / \mathrm{kg}$ DM and different phospholipid:neutral lipid values. The best growth (32 mg at the end of the experiment) survival $(73 \%)$ and larval quality (only $2 \%$ of malformed larvae) were obtained in the larvae fed the diet containing $116 \mathrm{~g}$ phospholipid/kg DM $(P<0 \cdot 05)$. These results were related to the amount of phosphatidylcholine and phosphatidylinositol included in this diet (35 and $16 \mathrm{~g} / \mathrm{kg}$ respectively). Amylase, alkaline phosphatase and aminopeptidase $\mathrm{N}$ activities revealed a proper maturation of the digestive tract in the two groups fed the highest phospholipid levels. Regulation of lipase and phospholipase A2 by the relative amount of their substrate in the diet occurred mainly at the transcriptional level. The response of pancreatic lipase to dietary neutral lipid was not linear. As in mammals $200 \mathrm{~g}$ triacylglycerol $/ \mathrm{kg}$ diet seems to represent a threshold level above which the response of pancreatic lipase is maximal. The response of phospholipase A2 to dietary phospholipid content was gradual and showed a great modulation range in expression. Sea bass larvae have more efficient capacity to utilize dietary phospholipid than neutral lipids. For the first time a compound diet sustaining good growth, survival and skeletal development has been formulated and can be used in total replacement of live prey in the feeding sequence of marine fish larvae.
\end{abstract}

Dicentrarchus labrax: Fish larvae development: Phospholipase A2: Phospholipids

A high increase in farmed fish production is expected during the next few years. But fry availability is still a bottleneck for the development of marine aquaculture industry. As the capture of wild seed for fish aquaculture cannot increase without ecological consequences, the only alternative is the production of fry in hatcheries (Naylor et al. 2000). For the moment, production in the hatchery relies on a live prey feeding sequence. The main live preys used are copepods and a small Crustacea Branchiopod, Artemia, which are caught from the wild. The use of live prey presents several disadvantages such as high cost (for Artemia), low reliability in production and variable nutritional quality. The main objective in fish larval nutrition is to formulate a compound diet that can be substituted for live prey as early as possible during larval development (Watanabe \& Kiron, 1994). This inert diet must be attractive enough for the larvae, with a diameter adapted to larvae mouth size, and must meet the nutritional requirement of fish larvae.

For years, experiments in larval nutrition have been conducted with dietary formulations close to those used for juvenile stages. But the diets leading to good performances in juveniles induced high mortality and very poor growth in larvae. It has been hypothesized that marine fish larvae have insufficient digestive capacity to thrive on a compound diet (Lauff \& Hofer, 1984). More recently, it has been shown that marine fish larvae have digestive features different from that of juveniles (Cahu \& Zambonino Infante, 1995). The change from a primary to an adult mode of digestion characterizes developing animals and has been extensively described in upper vertebrates (Henning, 1987). Therefore, research has been undertaken to understand specificities in digestion in order to determine specific nutritional requirements of larvae. In particular, the molecular form of protein supply has been extensively studied (Zambonino Infante et al. 1997). Studies concerning lipid requirement, and particularly phospholipid, have been initiated by Kanazawa et al. (1981, 1983). Recently, Zambonino Infante \& Cahu (1999) showed that high dietary lipid level improved sea bass (Dicentrarchus labrax) development and demonstrated that larvae have a high capacity to

Abbreviations: DHA, docosahexaenoic acid; EPA, eicosapentaenoic acid; GAPDH, glyceraldehyde-3-phosphate dehydrogenase; PCR, polymerase chain reaction; PL3, diet with $27 \mathrm{~g}$ phospholipids/kg; PL6, diet with $60 \mathrm{~g}$ phospholipids/kg; PL9, diet with $91 \mathrm{~g}$ phospholipids/kg; PL12, diet with $116 \mathrm{~g}$ phospholipids/kg; PLA2, phospholipase A2; RT, reverse transcriptase.

* Corresponding author: Dr Chantal L. Cahu, fax +3302982246 53, email ccahu@ifremer.fr 
utilize phospholipids. Moreover, Geurden et al. (1997a) have shown that the different phospholipids affect fish larvae development. These authors conducted the study with fresh water species, for which compound diets are already available. Data on the requirement for the different types of lipid have been put forward also for marine fish species (Sargent et al. 1999) but the range of values obtained by using enriched live prey as experimental diet was wide (Izquierdo et al. 2000).

The aim of the present study was to determine the influence of dietary phospholipid level and phospholipid:neutral lipid value on survival and development in marine fish larvae. The experimental design was based on sea bass larvae fed isolipidic and isoproteic microdiets from first feeding.

\section{Materials and methods}

\section{Animals and diets}

Eggs of European sea bass were obtained from Aquanord (Gravelines, France). Larval rearing was conducted at the Ifremer-Station de Brest and lasted $40 \mathrm{~d}$, which corresponds to the end of larval development. Newly hatched larvae were transferred from incubators to twenty conical fibreglass tanks (35 litres) with black walls (initial stocking density of sixty larvae/l, i.e. 2100 larvae per tank). They were supplied with running sea water, which had been filtered through a sand filter, then passed successively through a tungsten heater and a degassing column packed with plastic rings. Throughout the experiment, the water temperature and salinity were $20^{\circ} \mathrm{C}$ and $35 \mathrm{~g} \mathrm{NaCl} / \mathrm{l}$ respectively. The $\mathrm{O}_{2}$ level was maintained above $6 \mathrm{mg} / \mathrm{l}$ by setting the water exchange up to $30 \% / \mathrm{h}$ (flow rate 0.18 litres $/ \mathrm{min}$ ). The light intensity was $9 \mathrm{~W} / \mathrm{m}^{2}$ maximum at the surface. All animal procedures and handling were conducted in compliance with the Guide for the Care and Use of Laboratory Animals (National Research Council, 1985).

Larvae were distributed into sixteen tanks before mouth opening (day 6 post-hatching). Tank randomization was conducted at the start of the experiment; four tanks per dietary group. Larvae were fed from day 9 to day 40 post-hatching with a dry microdiet (patent WO0064273, 2 November 2000) containing ( $\mathrm{g} / \mathrm{kg}$ ): fish meal 560; fish meal hydrolysate (provided by La Lorientaise, Lorient, France) 140; vitamin mixture 80; mineral mixture 40 (mixes supplied according to Gouillou-Coustans \& Guillaume, 2001). Diets of the four groups incorporated increasing levels of soyabean lecithin (Nickerson, Marne la Vallée, France) and decreasing levels of fish oil (La Lorientaise) and were designated as PL3, PL6, PL9 and PL12 (Table 1). Microdiets were processed as follows: dietary ingredients were mechanically mixed with water, pelleted and dried at $50^{\circ} \mathrm{C}$ for $20 \mathrm{~min}$. The pellets were sieved to obtain two sizes of particles; $125-200 \mu \mathrm{m}$ used during the first $5 \mathrm{~d}$ then $200-400 \mu \mathrm{m}$ until the end of the experiment. Fish were continuously fed in excess for $18 \mathrm{~h} / \mathrm{d}$ using a belt feeder. Food ingestion was monitored by observing the larvae digestive tract under a binocular microscope; dietary microparticles being visible by transparency.
Table 1. Added lipid and composition of the lipid fraction in the experimental diets ( $\mathrm{g} / \mathrm{kg}$ dry diet)

\begin{tabular}{lrrrr}
\hline Diet... & PL3 & PL6 & PL9 & PL12 \\
\hline Added lipid in diets & & & & \\
$\quad$ Soyabean lecithin & 0 & 56 & 111 & 167 \\
$\quad$ Fish oil & 167 & 111 & 56 & 0 \\
Lipid composition & & & & \\
$\quad$ Neutral lipids & 229 & 203 & 173 & 137 \\
Phospholipids & 27 & 60 & 91 & 116 \\
Phosphatidylcholine & 9 & 18 & 26 & 35 \\
Phosphatidylinositol† & 2 & 7 & 12 & 16 \\
EPA+DHA & 49 & 36 & 24 & 15 \\
\hline
\end{tabular}

PL3, diet with $27 \mathrm{~g}$ phospholipids/kg; PL6, diet with $60 \mathrm{~g}$ phospholipids $/ \mathrm{kg}$; PL9, diet with $91 \mathrm{~g}$ phospholipids $/ \mathrm{kg}$; PL12, diet with $116 \mathrm{~g}$ phospholipids/kg; EPA, eicosapentaenoic acid; DHA, docosahexaenoic acid.

Soyabean lecithin, provided by Nickerson (Marne-la-Vallée, France), contains $620 \mathrm{~g}$ phospholipid/kg, including $260 \mathrm{~g}$ phosphatidylcholine, $200 \mathrm{~g}$ phosphatidylethanolamine and $140 \mathrm{~g}$ phosphatidylinositol $/ \mathrm{kg}$.

† Value calculated from raw material specifications.

Assayed composition of the diets was (g/ $\mathrm{kg} \mathrm{DM})$ : protein 584; lipid 260; ash 120 . So, diets differed only by their lipid composition. Phospholipid and neutral lipid contents in the diets were assayed by the Juaneda \& Roquelin (1985) method and eicosapentaenoic acid (EPA) and docosahexaenoic acid (DHA) concentration of the diet total lipid was determined by GLC (Varian.3400 gas chromatograph equipped with a DB Wax fused silica capillary column; Varian SA, Les Ulis, France).

\section{Sampling and dissection}

To monitor growth, ten larvae per tank (four tanks for each dietary group) were taken once weekly from each tank. For this, water volume was lowered and ten larvae were collected at one time using an appropriate net. These ten larvae were representative of the tank population. At the end of the experiment, larval survival rates were determined by counting individuals. Sixty larvae/tank (four tanks per treatment) were sampled and examined under a binocular microscope to determine spinal malformation, i.e. scoliosis, lordosis and coiled vertebral column. The malformation rate in each tank was determined as follows: number of malformed larvae/sixty larvae) $\times 100$.

At day 9 and day 40, fifty larvae were collected for enzymic studies from each tank before morning food distribution; larvae were immediately stored at $-80^{\circ} \mathrm{C}$ pending dissection and assays. Fifty larvae were collected for mRNA studies from only three tanks per dietary treatment; these were dissected and RNA extraction was immediately performed.

Dissection under the microscope was conducted on a glass maintained at $0^{\circ} \mathrm{C}$; individuals were cut into four parts as described by Cahu \& Zambonino Infante (1994): head, pancreatic segment, intestinal segment and tail, in order to limit the assay of enzymes to specific segments. This dissection inevitably produced a crude mixture of organs in each segment. The pancreatic segment, besides pancreas, contained liver, heart muscle and spine. The intestinal segment contained intestine, muscle and spine. 


\section{Analytical methods}

The pancreatic segments were homogenized into 5 vol. (v/w) of ice-cold distilled water. Amylase (EC 3.2.1.1) activity was assayed according to Métais \& Bieth (1968). Phospholipase A2 (PLA2; EC 3.1.1.4) was assayed by the reverse-phase HPLC method of Tojo et al. (1993). Lipase (EC 3.1.1.3) was assayed according to Iijima et al. (1998). Alkaline phosphatase (EC 3.1.3.1) and aminopeptidase $\mathrm{N}$ (EC 3.4.11.2), two enzymes of the brush-border membrane, were assayed according to Bessey et al. (1946) and Maroux et al. (1973), respectively. Purified brush-border membranes from the intestinal segment homogenate were obtained according to a method developed for intestinal scraping (Crane et al. 1979). The degree of purification of the brush-border membrane, taking alkaline phosphatase as a marker of cell membrane fraction, was close to that reported by Crane et al. (1979), i.e. 13.5-fold. Enzyme activities were expressed as specific activities, i.e. $\mu \mathrm{mol}$ hydrolysed substrate for alkaline phosphatase, aminopeptidase N, lipase and PLA2. Amylase activity was expressed as the equivalent enzyme activity required to hydrolyse $1 \mathrm{mg}$ starch during $30 \mathrm{~min}$ at $30^{\circ} \mathrm{C}$. Protein was determined by the Bradford procedure (Bradford, 1976).

\section{Reverse transcriptase-polymerase chain reaction analysis}

Total RNA was extracted using the TRIzol ${ }^{\circledR}$ reagent kit procedure (Life Technologies, Grand Island, NY). For synthesis of cDNA, $5 \mu \mathrm{g}$ total RNA was treated with FPLCpure Moloney-Murine Leukaemia virus reverse transcriptase (RT) using the Ready-To-Go-T-Primed First Strand Kit (Pharmacia Biotech, Uppsala, Sweden). Polymerase chain reaction $(\mathrm{PCR})$ was carried out by an initial denaturation at $94^{\circ} \mathrm{C}$ for $1 \mathrm{~min}$, followed by thirty cycles at temperatures of $94^{\circ} \mathrm{C}$ for $30 \mathrm{~s}$, specific annealing temperatures for $1.5 \mathrm{~min}$ and $72^{\circ} \mathrm{C}$ for $1 \mathrm{~min}$; the final extension was conducted at $72^{\circ} \mathrm{C}$ for $7 \mathrm{~min}$. PCR mixture contained $0.8 \mu \mathrm{l}$ cDNA, 0.2 units Taq Polymerase (Appligene, Gaithersburg, MD), $100 \mu \mathrm{mol}$ dNTP (deoxyribonucleotide triphosphate)/l, $50 \mu \mathrm{mol}$ each primer and 1X Reaction Buffer (Appligene), in a final volume of $50 \mu \mathrm{l}$. Sequences and annealing temperatures for the sense and antisense oligonucleotides were: 5'-gCCATCAATgACCCCTT-3' and 5'-ggTgCAggATgCATTgC- $3^{\prime}\left(50^{\circ} \mathrm{C}\right)$ for glyceraldehyde-3-phosphate dehydrogenase (GAPDH); 5'-ACTACggYTgCTACTg- $3^{\prime}$ and $5^{\prime}$-CggTCACAgTTRCAgA- $3^{\prime}\left(48^{\circ} \mathrm{C}\right)$ for PLA2; $5^{\prime}-$ TgTggCTTCAACAgC- $3^{\prime}$ and $5^{\prime}$-CgCTCCAAgRCTgTA$3^{\prime}\left(50^{\circ} \mathrm{C}\right)$ for lipase, respectively.

These primers have been selected after alignment of different species sequences of selected mRNA, obtained using the Sequence Retrieval System WWW server at EMBL-EBI (European Molecular Biology LaboratoryEuropean Informatics Institute, Cambridge, UK). Alignments of RNA sequence of species from different phyla were necessary as fish RNA sequences were scarce. The resulting PCR products have been cloned using the TOPO-TA Cloning kit (Invitrogen, Leek, The Netherlands) and sequenced by Cybergene (St Malo, France); the obtained GAPDH, PLA2 and lipase sequences have been registered by EMBL under AJ006883, AJ006339 and AJ275976 accession numbers, respectively.

GAPDH, PLA2 and lipase were amplified using the same cDNA sample; 1 to $10 \mu$ l each PCR product were applied on an agarose $(1.2 \%)$-ethidium bromide $(1 \mathrm{mg} / \mathrm{l})$ gel. cDNA spots were quantified with a Fluor-S ${ }^{\mathrm{TM}}$ Multilmager and its MultiAnalyst Software (BIORAD, Hercules, CA) using appropriate calibration. We generated a standard curve by plotting the u.v. absorbance of the spots (resulting after a thirty-cycle PCR) against the input concentration of the studied cDNA. The limits of the exponential phase and the beginning of the saturation phase of the amplification reaction were determined for each gene to ensure the linear relationship between input RNA and final RT-PCR product. The obtained values of PLA2 and lipase mRNA were normalized relative to the GAPDH mRNA, by the calculation of the PLA2:GAPDH mRNA value and the lipase:GAPDH value. Indeed, Sölch \& Arnold (1996) have shown that this normalization relative to GAPDH provides a widely applicable value for comparative studies of gene expression at the mRNA level.

\section{Statistical analyses}

Results are given as mean values and standard deviations ( $n$ 4; $n 3$ for mRNA studies). Survival rates, malformation rates and values of mRNA were $\arcsin \left(\mathrm{x}^{1 / 2}\right)$ transformed. The variance homogeneity of the data was checked using Bartlett's test (Dagnelie, 1975). Larvae weight, survival rate and values of enzymic segmental activity data were compared by a one-way ANOVA followed by the Newman-Keuls multiple range test (Dagnelie, 1975) when significant differences were found at the $(P<0.05)$ level.

\section{Results}

The microdiets were efficiently ingested by the larvae of the four dietary treatments from starting exogenous feeding. A marked difference appeared in larval growth among the experimental groups. The higher the dietary phospholipid content, the greater the growth $(P<0.05)$. Larval final weight in the group fed PL12 was 18-fold higher than in the group fed the PL3 diet (Fig. 1).

Survival rate was graded in the same order and went beyond $73 \%$ in the PL12 group (Table 2). Concurrently, very few larvae exhibited malformation at the end of the experiment in the PL12 treatment. The rate of spinal malformations (scoliosis, lordosis, coiled vertebral column) became significantly higher $(P<0.05)$ when dietary phospholipid level was lower. More than one-third of the surviving larvae exhibited skeletal malformations in the PL3 treatment, while malformation rate reached only $2 \%$ in the PL12 treatment. The best results in growth, survival and larvae quality were obtained in the group fed PL12 containing $116 \mathrm{~g}$ phospholipid/ $/ \mathrm{kg}$, and including $35 \mathrm{~g}$ phosphatidylcholine and $16 \mathrm{~g}$ phosphatidylinositol/kg (Table 1 ).

Amylase specific activity sharply decreased during development (Table 2). Activities in 40-d-old larvae were from $2 \cdot 5$ - to $5 \cdot 3$-fold reduced relative to that assayed in 


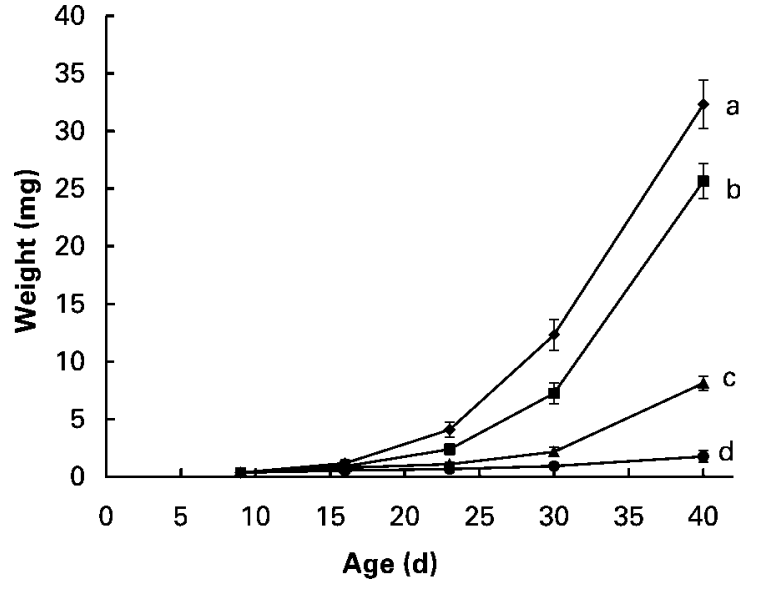

Fig. 1. Growth of sea bass (Dicentrarchus labrax) larvae fed isoproteic and isolipidic diets containing different phospholipid levels: $27 \mathrm{~g} / \mathrm{kg}$ diet $(-\bullet-) ; 60 \mathrm{~g} / \mathrm{kg}$ diet $(-\Delta-) ; 91 \mathrm{~g} / \mathrm{kg}$ diet $(-\boldsymbol{-}) ; 116 \mathrm{~g} / \mathrm{kg}$ diet $(--)$. Mean values are shown with standard deviations represented by vertical bars $(n 4)$. ${ }^{a, b, c, d}$ Mean values with unlike superscript letters for the same day are significantly different $(P<0.05)$. For details of diets and procedures, see Table 1 and p. 22.

9-d-old ones. At the end of the experiment, larvae fed diets containing high phospholipid levels (91 and $116 \mathrm{~g} / \mathrm{kg} \mathrm{DM}$ ) showed a lower amylase specific activity than groups fed low phospholipid levels (27 and $60 \mathrm{~g}$ phospholipids/kg). Activities of alkaline phosphatase and aminopeptidase $\mathrm{N}$ in brush-border membranes of enterocytes were higher $(P<0.05)$ and similar in larvae fed diets PL9 and PL12 relative to those assayed in larvae fed diets PL6 and PL3. In general, there was a trend towards increasing enzyme activities as the level of dietary phospholipid increased (Table 2).

Lipase-specific activity of larvae was affected by the triacylglycerol level in the diet (Fig. 2 (A)). Groups fed the PL3 and PL6 diets, incorporating high neutral lipid levels (229 and $203 \mathrm{~g} / \mathrm{kg} \mathrm{DM}$ ), exhibited a lipase activity four times higher than groups fed PL9 and PL12 (incorporating low neutral lipid levels, 173 and $137 \mathrm{~g} / \mathrm{kg}$ DM, respectively). The lipase:GAPDH mRNA values were also higher in groups fed high neutral lipid levels than in the other groups, but the differences were less pronounced (Fig. 2 (B)).

PLA2 specific activity was highly influenced by the dietary phospholipid level (Fig. 3 (A)). A 9-fold increase in phospholipid activity was observed comparing the PL3 and PL12 groups. The value of PLA2:GAPDH mRNA was higher in the group fed the highest phospholipid level (PL12) than in the group fed the lowest phospholipid level (Fig. 3 (B)). Nevertheless, the range of variation in the phospholipase mRNA value was less important than variations in phospholipase activity.

\section{Discussion}

The present study described a feeding experiment of marine fish larvae using exclusively a dry microdiet. The previous attempts of compound diet feeding as early as fish larvae mouth opening have reported high mortality and poor growth (Cahu et al. 1998; Yufera et al. 1999). The determination of dietary requirement and the formulation of a diet for marine fish larvae represented for several years a major objective of many laboratories. In contrast, diet formulation has been easily achieved for some freshwater species larvae, which are bigger at hatching.

The tested diets, only differing by their lipid mixture composition, greatly affected both growth and survival of sea bass larvae. The most efficient diet induced a survival (73\%) that is higher than that generally observed with live prey feeding. Interestingly, this high survival result corresponded with a growth performance (32 $\mathrm{mg}$ at day 40 ) similar to that generally obtained with an Artemia feeding sequence. Indeed, sea bass larvae fed live prey, and reared in the same laboratory conditions in several experiments, reached around 30 to $35 \mathrm{mg}$ at day 40, with $50 \%$ survival (Cahu \& Zambonino Infante, 1994, 1995; Zambonino Infante et al. 1996). At the same age, weight of sea bass larvae produced in the hatchery hardly goes beyond $25 \mathrm{mg}$ with a maximum of $40 \%$ survival. Moreover, the good survival and growth was associated with a low number of skeletal malformations. Around $30 \%$ of marine fish larvae reared in hatcheries exhibit deformities (Andrades et al. 1996). A great number of factors, such

Table 2. Survival and malformation rates of 40 -d-old sea bass (Dicentrarchus labrax), and specific activities of amylase, alkaline phosphatase and aminopeptidase in 9- and 40-d-old sea bass larvae fed the four experimental diets*

(Mean values and standard deviations)

\begin{tabular}{|c|c|c|c|c|c|c|c|c|c|c|}
\hline \multirow{2}{*}{ Diet... } & \multirow{2}{*}{\multicolumn{2}{|c|}{$\begin{array}{c}\text { Day } 9 \\
\text { Initial }\end{array}$}} & \multicolumn{8}{|c|}{ Day 40} \\
\hline & & & \multicolumn{2}{|c|}{ PL3 } & \multicolumn{2}{|c|}{ PL6 } & \multicolumn{2}{|c|}{ PL9 } & \multicolumn{2}{|c|}{ PL12 } \\
\hline Survival (\%) & & & $22^{c}$ & $1 \cdot 0$ & $52^{b}$ & $7 \cdot 3$ & $60^{\mathrm{b}}$ & $1 \cdot 3$ & $73^{a}$ & $6 \cdot 5$ \\
\hline Malformation (\%) & & & $35^{a}$ & 4.5 & $20^{\mathrm{b}}$ & $3 \cdot 3$ & $15^{\mathrm{b}}$ & $2 \cdot 1$ & $2^{\mathrm{c}}$ & $1 \cdot 0$ \\
\hline Amylase (U/mg protein) & $3 \cdot 2^{a}$ & 0.21 & $1 \cdot 3^{b}$ & 0.27 & $1 \cdot 3^{\mathrm{b}}$ & 0.28 & $0.7^{c}$ & 0.06 & $0.6^{\mathrm{c}}$ & 0.04 \\
\hline Aminopeptidase $\mathrm{N}$ (mU/mg protein) & ND & & $42^{\mathrm{C}}$ & $9 \cdot 2$ & $109^{b}$ & $15 \cdot 4$ & $172^{\mathrm{a}}$ & 21.9 & $200^{a}$ & $16 \cdot 5$ \\
\hline
\end{tabular}

PL3, diet with $27 \mathrm{~g}$ phospholipid/kg; PL6, diet with $60 \mathrm{~g}$ phospholipid $/ \mathrm{kg} ; \mathrm{PL9}$, diet with $91 \mathrm{~g}$ phospholipid/kg; PL12, diet with $116 \mathrm{~g}$ phospholipid/kg; ND, not detected.

${ }^{a, b, c}$ Mean values within a row with unlike superscript letters were significantly different $(P<0.05)$.

* For details of diets and procedures, see Table 1 and p. 22. 

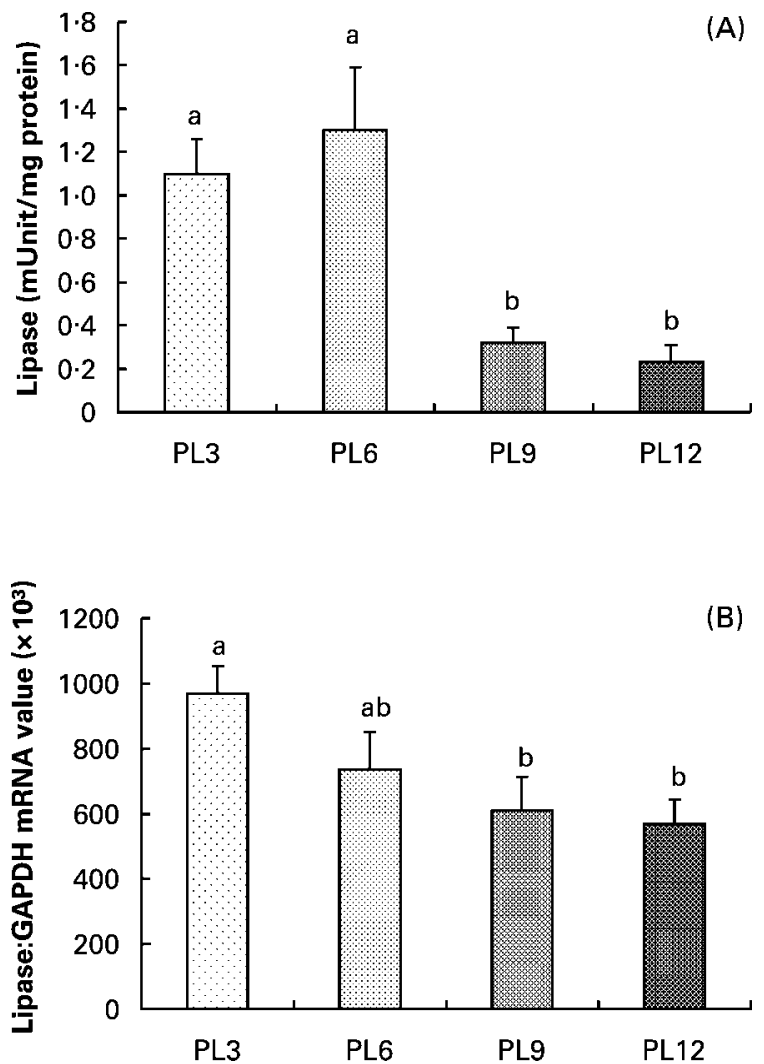

Fig. 2. Specific activity of lipase $(A)$ and value of lipase mRNA:glyceraldehyde-3-phosphate dehydrogenase (GAPDH) mRNA (B) in 40-d-old sea bass (Dicentrarchus labrax) larvae fed isoproteic and isolipidic diets containing 27,66, 91 and $116 \mathrm{~g}$ phospholipid and 229, 203, 173 and $137 \mathrm{~g}$ neutral lipid/kg dry diet (PL3, PL6, PL9 and PL12 respectively). Mean values are shown, with standard deviations represented by vertical bars ( $n 4$ for specific activity; $n 3$ for mRNA value). Mean values with unlike superscript letters are significantly different $(P<0.05)$. For details of diets and procedures, see Table 1 and p. 23.

as genetic or environmental parameters, have been supposed to affect skeletal formation (Divanach et al. 1996). Among these factors, the influence of diet on larval malformation has been experimentally demonstrated. It has been shown in particular that vitamins (retinol and ascorbic acid) and protein (peptide chain length) can affect skeletal development in marine fish larvae. The basal diet was formulated to meet protein and amino acid requirements of sea bass larvae (Péres et al. 1996) and vitamin requirements of fish (Gouillou-Coustans \& Guillaume, 2001). The present study shows that the phospholipid content relative to the total lipid in the diet also influences the skeletal formation process. A supply of $253 \mathrm{~g}$ neutral lipids/kg including $116 \mathrm{~g}$ phospholipids/kg (diet PL12) led to a very low percentage of deformities. When the phospholipid:total lipid value was lowered, the rate of malformed larvae increased. In a previous experiment (CL Cahu and JL Zambonino Infante, unpublished results), no differences were observed in sea bass larvae fed diets containing increasing fat levels with a constant level of phospholipid $(230 \mathrm{~g} / \mathrm{kg}$ total lipid). Taking these data together, it appears that the malformation rate is more
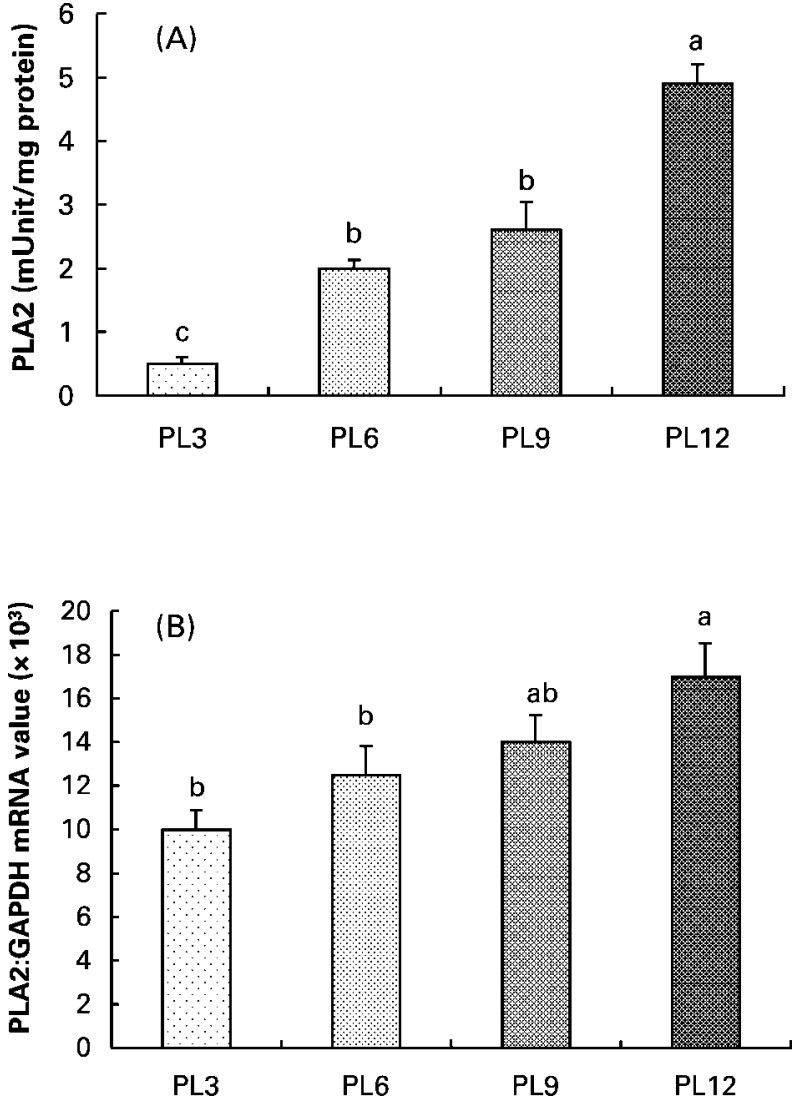

Fig. 3. Specific activity of phospholipase A2 (PLA2; A) and value of PLA2 mRNA:glyceraldehyde-3-phosphate dehydrogenase (GAPDH) mRNA (B) in 40-d-old sea bass larvae fed isoproteic and isolipidic diets containing different phospholipid levels: $27 \mathrm{~g} / \mathrm{kg}$ diet (PL3); $60 \mathrm{~g} / \mathrm{kg}$ diet (PL6); $91 \mathrm{~g} / \mathrm{kg}$ diet (PL9); $116 \mathrm{~g} / \mathrm{kg}$ diet (PL12). Mean values are shown, with standard deviations represented by vertical bars ( $n 4$ for specific activity; $n 3$ for mRNA value). Mean values with unlike superscript letters are significantly different $(P<0.05)$. For details of diets and procedures, see Table 1 and p. 23.

linked to the proportion of phospholipid:neutral lipid than to the overall lipid content in the diet.

Several studies conducted on different fish species (Kanazawa et al. 1981, 1983; Shield et al. 1999) showed that fish do require dietary phospholipid, and the requirement seems to be higher in larvae than in juveniles (Kanazawa, 1993). Moreover, Geurden et al. (1997a, 1998) suggested that phosphatidylcholine has a growthpromoting effect and phosphatidylinositol prevents deformity in carp (Cyprinus carpio) larvae. But our study was not designed in order to obtain more information on the role of the different phospholipid classes.

The present study demonstrated that phospholipid from vegetable sources can be used in diets for marine fish larvae, though they do not contain highly unsaturated fatty acids. Geurden et al. (1997b) arrived at the same conclusions with young juvenile sea bass. A small amount of marine phospholipids including high levels in highly unsaturated fatty acids, mainly EPA and DHA, were incorporated in diets by fishmeal and fishmeal hydrolysate. This small amount was sufficient to allow good larval 
growth and survival. Marine phospholipid appeared to be essential for fish larvae development (Sargent et al. 1999). Nevertheless, we demonstrated that the efficiency of phospholipid in larvae development could not be attributed to their EPA and DHA content. A concentration of $15 \mathrm{~g} \mathrm{EPA}+$ DHA/kg DM (diet PL12) is sufficient to sustain good larvae development. The value found in the present study is much lower than the minimal level, $27 \mathrm{~g} / \mathrm{kg}$, recommended until now in the literature (Sargent et al. 1999; Zambonino Infante \& Cahu, 1999).

Anatomical and functional development of larval tissues continues during the first month of life in marine fish. In particular, larvae change from a primary to an adult mode of digestion (Cahu \& Zambonino Infante, 1995). Amylase expression can be considered as an indicator of the maturation of the exocrine pancreas. A decline of amylase is observed during the normal maturation process (Péres et al. 1998). This pattern can be compared with the decline of lactase expression normally observed during early development in mammals (Freund et al. 1990). The intestine also undergoes a maturation process. In early larval stages, enterocyte microvilli are poorly developed, with low activities of brush-border-membrane enzymes. During the third week of sea bass development, brush-border-membrane enzymes, such as alkaline, phosphatase or aminopeptidase $\mathrm{N}$, drastically increase (Cahu \& Zambonino Infante, 1995). In our study, amylase activity decreased from day 9 to day 40 in the four dietary groups, as expected. This decrease was more pronounced in the two groups fed high phospholipid levels. On the other hand, the highest enzyme activities in brush-border membranes were found in the groups fed the high phospholipid level. The activity of alkaline phosphatase observed at day 40 could be the result of an adaptation of the enzyme to one of its dietary substrates, phospholipid. But phospholipid is not a potential substrate for aminopeptidase $\mathrm{N}$, thus the high aminopeptidase $\mathrm{N}$ activities in groups fed the high phospholipid level reflected a proper development of digestion in brush-border membranes. These results suggest that dietary phospholipid levels affect pancreas and intestine maturation. The achievement of digestive tract maturation in developing animals, fish as well as mammals, must occur during a specific window of time. This is necessary for the proper development of the animal.

Expression of lipolytic enzymes, in our experiment was stimulated by the amount of their relative substrates in the diet. The regulation of lipase and PLA 2 occurred mainly at the transcriptional level, since the differences in enzymic activities globally reflected the different amounts of mRNA of the different groups. The transcriptional regulation has been previously evidenced for PLA2 (Zambonino Infante $\&$ Cahu, 1999). The present study shows transcriptional regulation for lipase in fish larvae, as described in mammals (Wicker et al. 1988). Nevertheless, an additional regulation seems to influence enzymic activities. Indeed, the activity of PLA2 increased linearly, but to a greater extent than the corresponding mRNA levels; a 9-fold increase in activity $v$. a 1.6-fold increase in mRNA level when comparing PL3 and PL12. An involvement of a post-transcriptional mechanism in PLA2 regulation could be possible. It has been already suggested (Zambonino Infante \& Cahu, 1999) that the efficiency of PLA2 mRNA translation could be modulated by cholecystokinin. Lipase activity is 4-fold higher in larvae fed high triacylglycerol levels compared with low triacylglycerol levels. This range of response is higher than in mammals, for which only a 2- to 3-fold variation was reported (Sabb et al. 1986). The response of pancreatic lipase to dietary fat is not linear. As in mammals, it seems that $200 \mathrm{~g}$ neutral lipid/kg diet (mostly triacylglycerol) set the threshold level above which substrate saturation of pancreatic lipase activity is likely to occur. This sharp augmentation in lipase activity could be, as for PLA2, the result of a hormonal regulation. An involvement of cholecystokinin in the stimulation of lipase expression cannot be considered since groups exhibiting a high lipase level have a low PLA2 level. These responses were induced by diet composition, triacylglycerol levels varying inversely to phospholipid levels. Among the gastrointestinal hormones acting in pancreatic secretion, secretin is particularly stimulated by dietary lipids (Scheele, 1994). The discoordinated response between mRNA and activity of lipase in the four dietary groups could be explained by secretin release.

The modulation of lipase response to neutral lipid amount in the diet was rather undefined. In contrast, the response of PLA2 to dietary phospholipid content was gradual and showed a greater modulation range in expression. This observation suggests that marine fish larvae have a more efficient capacity to utilize phospholipid than neutral lipids. Therefore, it would explain in part why a lipid supply mainly in phospholipid form is needed for larvae development. Shield et al. (1999) noted that phospholipids are more easily digested by halibut larvae than triacylglycerol and suggested an absolute requirement in developing fish. Indeed, several roles of phospholipid in developing fish larvae have been put forward: energy supply; facilitation of fat emulsification and digestion; enhancement of lipid transport between organs and settlement of cell membranes (Coutteau et al. 1997). Recently, a phospholipid requirement has also been reported in juvenile marine fish (Olsen et al. 1999).

In conclusion, a dry microdiet sustaining good growth, survival and harmonious larval development of a marine fish species has been formulated for the first time. The diet can be used from mouth opening, in total replacement of live preys. The present study showed that dietary phospholipid level is influential for sea bass development and that larvae have, since the earliest stages, an efficient regulation of lipolytic enzymes. The dietary role of phospholipid was shown to be to a great extent independent from their $n-3$ highly unsaturated fatty acid moiety. Nevertheless, the optimal phospholipid level remains to be found.

\section{Acknowledgements}

The authors wish to thank P. Quazuguel and M. M. Le Gall for their excellent technical assistance.

\section{References}

Andrades JA, Becerra J \& Fernandez-Llebrez P (1996) Skeletal deformities in larval, juvenile and adult stages of cultured gilthead sea bream (Sparus aurata L.). Aquaculture 141, 1-11. 
Bessey OA, Lowry OH \& Brock MJ (1946) Rapid coloric method for determination of alkaline phosphatase in five cubic millimeters of serum. J Biochem Chem 164, 321-329.

Bradford MM (1976) A rapid and sensitive method for the quantitation of microgram quantities of protein utilizing the principle of protein-dye binding. Anal Biochem 72, 248-254.

Cahu CL \& Zambonino Infante JL (1994) Early weaning of sea bass (Dicentrarchus labrax) larvae with a compound diet: effect on digestive enzymes. Com Biochem Physiol 109A, 213-222.

Cahu CL \& Zambonino Infante JL (1995) Maturation of the pancreatic and intestinal digestive functions in sea bass (Dicentrarchus labrax): effect of weaning with different protein sources. Fish Physiol Biochem 14, 431-437.

Cahu CL, Zambonino Infante JL, Escaffre AM, Bergot P \& Kaushik S (1998) Preliminary results on sea bass Dicentrarchus labrax larvae rearing with compound diet from first feeding. Comparison with carp (Cyprinus carpio) larvae. Aquaculture 169, 1-7.

Coutteau P, Geurden I, Camara MR, Bergot P \& Sorgeloos P (1997) Review on the dietary effects of phospholipids in fish and crustacean larviculture. Aquaculture 155, 149-164.

Crane RK, Boge G \& Rigal A (1979) Isolation of brush border membranes in vesicular form from the intestinal spiral valve of the small dogfish (Scyliorhinus canicula). Biochim Biophys Acta 554, 264-267.

Dagnelie P (1975) Les méthodes de l'inférence statistique. In Théorie et Méthodes Statistiques (Statistical Theory and Methods), vol. 2, pp. 1-463 [J Ducolot, editor]. Gembloux, Belgium: Les Presses Agronomiques de Gembloux.

Divanach P, Boglione C, Menu B, Komodouros G, Kentouri M \& Cataudella S (1996) Abnormalities in finfish mariculture: an overview of the problem, cause and solutions. In International Workshop on Sea Bass and Sea Bream Culture: Problems and Prospects, pp. 45-66 [B Chatain, M Saroglia, J Sweetman and P Lavens, editors]. Ostende, Belgium: European Aquaculture Society.

Freund JN, Torp N, Duluc I, Foltzer-Jourdaine C, Danielsen M \& Raul F (1990) Comparative expression of mRNA for three intestinal hydrolases during post-natal development in the rat. Cell Mol Biol 36, 729-736.

Geurden I, Charlon N, Marion D \& Bergot P (1997a) Influence of purified soybean phospholipids on early development of common carp. Aquaculture Int 5, 137-149.

Geurden I, Coutteau P \& Sorgeloos P (1997b) Increased docosahexaenoic acid (DHA) levels in total and polar lipid of European sea bass (Dicentrarchus labrax) postlarvae fed vegetable or animal phospholipids. Mar Biol 129, 489-498.

Geurden I, Marion D, Charlon N, Coutteau P \& Bergot P (1998) Comparison of different soybean phospholipidic fractions as dietary supplements for common carp, Cyprinus carpio, larvae. Aquaculture 161, 225-235.

Gouillou-Coustans MF \& Guillaume J (2001) Vitamin nutrition. In Nutrition and Feeding of Fish and Crustaceans, pp. 145-166 [J Guillaume, S Kaushik, P Bergot and R Métailler, editors]. Chichester, UK: Springer-Praxis Books.

Henning SJ (1987) Functional development of the gastrointestinal tract. In Physiology of the Gastrointestinal Tract, pp. 285-300 [LR Johnson, editor]. New York: Raven Press.

Iijima N, Tanaka S \& Ota Y (1998) Purification and characterization of bile salt-activated lipase from the hepatopancreas of the red sea bream, Pagrus major. Fish Physiol Biochem 18, 59-69.

Izquierdo MS, Socorro J, Arantzamendi L \& Hernandez-Cruz CM (2000) Recent advances in lipid nutrition in fish larvae. Fish Physiol Biochem 22, 97-107.

Juaneda P \& Roquelin G (1985) Rapid and convenient separation of phospholipid and non phosphorus lipids from rat heart using silica cartridges. Lipids 20, 40-41.
Kanazawa A (1993) Essential phospholipids of fish and crustaceans. In Fish Nutrition in Practice, pp. 519-530 [SJ Kaushik and $\mathrm{P}$ Luquet, editors]. IVth International Symposium on Fish Nutrition and Feeding Paris, France: INRA.

Kanazawa A, Teshima S, Inamori S, Iwashita $\mathrm{T} \&$ Nagao A (1981) Effect of phospholipids on growth, survival rate, and incidence of malformation in larval ayu. Mem Fac Fish, Kagoshima University 30, 301-309.

Kanazawa A, Teshima S, Inamori S \& Matsubara H (1983) Effects of dietary phospholipids on growth of the larval red sea bream and knife jaw. Mem Fac Fisheries, Kagoshima University 32, 109-114.

Lauff M \& Hofer R (1984) Development of proteolytic enzymes in fish and the importance of dietary enzymes. Aquaculture $\mathbf{3 7}$ 335-346.

Maroux S, Louvard D \& Baratti J (1973) The aminopeptidase from hog-intestinal brush border. Biochim Biophys Acta 321, 282-295.

Métais P \& Bieth J (1968) Détermination de l' $\alpha$-amylase par une microtechnique (Determination of $\alpha$-amylase by a microtechnique). Annal Biol Clin (Paris) 26, 133-142.

National Research Council (1985) Guide for the Care and Use of Laboratory Animals. Publication no. 85-23 (rev.). Bethesda, MD: National Institutes of Health.

Naylor RL, Goldburg RJ \& Primavera JH, et al. (2000) Effect of aquaculture on world fish supplies. Nature 405, 1017-1024.

Olsen RE, Myklebust R, Kaino T \& Ringo E (1999) Lipid digestibility and ultrastructural changes in the enterocytes of Arctic char (Salvinelus alpinus L.) fed linseed oil and soybean lecithin. Fish Physiol Biochem 21, 35-44.

Péres A, Cahu CL, Zambonino Infante JL, Le Gall MM \& Quazuguel P (1996) Amylase and trypsin response to dietary carbohydrate and protein level depends on the developmental stage in sea bass (Dicentrarchus labrax) larvae. Fish Physiol Biochem 15, 237-242.

Péres A, Zambonino Infante JL \& Cahu CL (1998) Dietary regulation of activities and mRNA levels of trypsin and amylase in sea bass (Dicentrarchus labrax) larvae. Fish Physiol Biochem 19, $145-152$.

Sabb JE, Godfrey PM \& Brannon PM (1986) Adaptative response of rat pancreatic lipase to dietary fat: effects of amount and type of fat. J Nutr 116, 892-899.

Sargent J, McEvoy L \& Estevez A, et al. (1999) Lipid nutrition of marine fish during early development: current status and future directions. Aquaculture 179, 217-229.

Scheele GA (1994) Extracellular and intracellular messengers in diet-induced regulation of pancreatic gene expression. In Physiology of the Gastrointestinal Tract, third edn, pp. 1543-1554 [LR Johnson and GA Scheele, editors]. New York, NY: Raven Press.

Shield RJ, Bell J, Luizi FS, Gara B, Bromage N \& Sargent JR (1999) Natural copepods are superior to enriched Artemia nauplii as feed for halibut larvae (Hippoglossus hippoglossus) in terms of survival, pigmentation and retinal morphology: relation to dietary essential fatty acids. $J$ Nutr $\mathbf{1 2 9}$, 1186-1194.

Sölch JP \& Arnold GJ (1996) Multiplex reverse transcription polymerase chain reaction combined with temperature gradient gel electrophoresis as a tool for the normalized quantification of intrinsic factor mRNA. Electrophoresis 17, 30-39.

Tojo H, Ono T \& Okamoto M (1993) Reverse-phase high-performance liquid chromatographic assay of phospholipases: application of spectrophotometric detection to rat phospholipase A2 isoenzymes. J Lipid Res 34, 837-844.

Watanabe T \& Kiron V (1994) Prospects in larval fish dietetics. Aquaculture 124, 223-251. 
Wicker C, Scheele GA \& Puigserver A (1988) Pancreatic adaptation to dietary lipids is mediated by changes in lipase mRNA. Biochimie 70, 1277-1283.

Yufera M, Fernandez-Diaz C \& Pascual E (1999) A highly efficient microencapsulated food for rearing early larvae of marine fish. Aquaculture 177, 249-256.

Zambonino Infante JL \& Cahu CL (1999) High dietary lipid levels enhance digestive tract maturation and improve Dicentrarchus labrax larval development. J Nutr 129, 1195-1200.
Zambonino Infante JL, Cahu CL \& Péres A (1997) Partial substitution of di- and tripeptides for native protein in sea bass diet improves Dicentrarchus labrax larval development. J Nutr 127, 604-614.

Zambonino Infante JL, Péres A, Cahu CL, Quazuguel P \& Le Gall MM (1996) Sea bass (Dicentrarchus labrax) larvae fed different Artemia rations: growth, pancreas enzymatic response and development of digestive functions. Aquaculture 139, 129-138. 